\title{
Additive process chain: From virtual design to real implementation
}

\author{
Martin Rambke ${ }^{1}$, Sven Lippardt ${ }^{1}$, Tobias Mussehl ${ }^{1}$ \\ ${ }^{1}$ Ostfalia University of Applied Sciences, faculty of mechanical engineering, Salzdahlumer Straße 46/48, 38302 \\ Wolfenbüttel, Germany
}

\begin{abstract}
In the course of the digital transformation, many companies are now striving to link virtual development and production processes with each other. The authors of this article want to discuss the following findings in the area of "additive manufacturing":

For the production of new components (in this research a node connection for a bicycle frame is used), it is often necessary to pay attention to the special features of additive manufacturing already during the design phase. Topology optimization software (MSC Apex Generative Design, former: AMendate) is used for a load-compliant design of the components in order to save material and thus reduce the production time. The designs must also be checked and compensated for distortions caused by production-related residual stresses (Simufact Additive). A validation of the distortion compensation is carried out after the production by an optical measurement of the component (Aicon). The strength and stiffness of the topology-optimized structure is verified by a test setup.
\end{abstract}

\section{Introduction}

At the Ostfalia University of Applied Sciences there are currently about 12,400 students studying in 12 faculties at four locations (Salzgitter, Suderburg, Wolfenbüttel and Wolfsburg). At the Institute for Production Technology (IPT) of the Faculty of Mechanical Engineering, seven professors and 16 research assistants are currently working in teaching and research. Four years ago, the Fabrication Laboratory (www.FabLab38.de) was initiated, which in 2017 - with the participation of other faculties - led to the foundation of the Center for Additive Manufacturing (ZaF). On meanwhile 25 "3D printers", student projects and research work in various processes (FDM, SLA, SLS, Polyjet etc.) are realized. Also in 2017, a Renishaw AM400 was applied for and procured as part of an EFRE infrastructure measure, which enables production with metal laser sintering (SLM) [1].

\section{State of the art}

In additive manufacturing, new components are currently being tested according to the trial and error principle.
The components are manufactured based on their original design and then a target-performance comparison is carried out. If too large deviations occur, a redesign of the component is necessary to compensate the resulting distortions. This process is repeated until the deviations of the component are within the specified tolerance. This procedure wastes a lot of time in testing before the final design of the component is determined. Figure 1 shows the testing procedure so far. In addition to the wasted development time, both manufacturing capacity and material are lost due to the production of scrap parts.

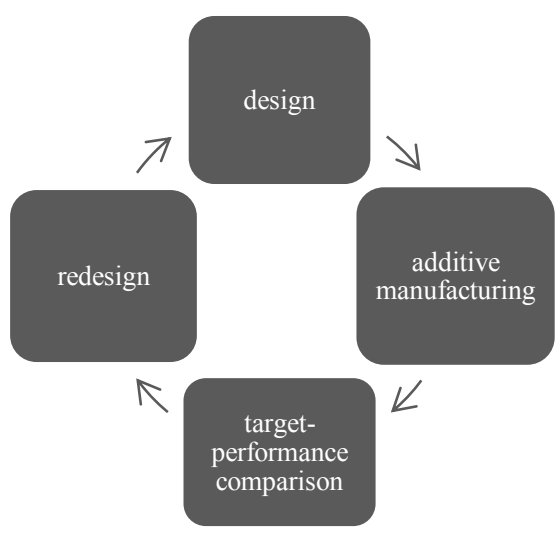

Figure 1: Procedure so far

\section{Aim of the research projekt}

In order to improve additive manufacturing, it is necessary to consider the entire process chain. For the implementation of the real process chain a virtual design is necessary to prevent errors in the real manufacturing process, to increase productivity and to minimize costs. The virtual design of the additive manufacturing process takes place in three steps. First, the existing design is adapted to the real load case with the help of topology optimization (MSC Apex Generative Design) in order to reduce the component weight and decrease the manufacturing time (Chapter 2). In the second step an optimization of the component alignment and the required 
support structures is carried out (Chapter 3). Finally, a simulation of the additive manufacturing process is carried out (Simufact Additive) in order to examine the component for residual stresses and resulting distortion and to compensate them if necessary (Chapter 3). For the validation of the prozess the compensated components are manufactured and subsequently measured (Aicon). The measurement results are compared with the target component and the simulation results (Chapter 4). To check the component strength, the topologyoptimized component is loaded on a test bench with the real load cases (Chapter 5). The aim is to establish a continuous process chain.

\section{Topology optimization of the component}

For a meaningful topology optimization of the component used, the design must first be checked. This check is necessary because the design geometry represents the design space for topology optimization. Inside the design space it is possible to remove excess material, but not to add outside. In addition to the design space, "nondesign spaces" must be specified for the preparation of the topology optimization. Figure 2 shows the procedure for this.

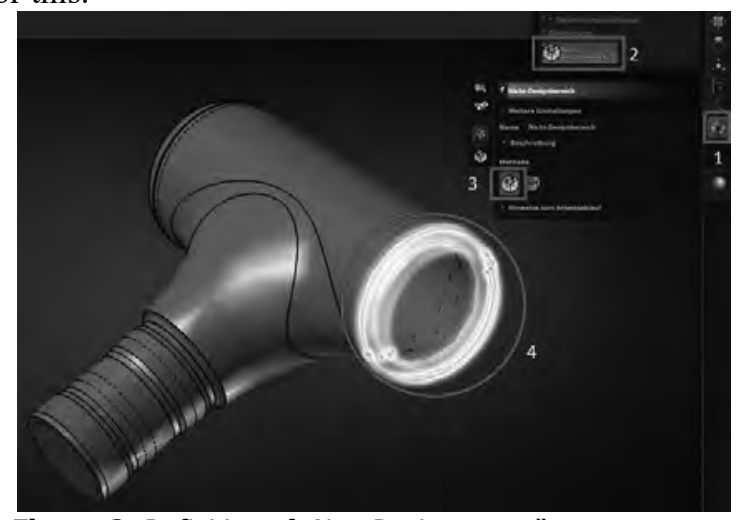

Figure 2: Definition of "Non-Designspaces"

The "Non-Designspaces" are needed for the definition of bearing and connection areas, as this material is absolutely necessary and is left out of the design space.

After the "Non-Designspaces" are defined, the occurring loads are defined. Figure 3 shows an example of the definition of a force on the component to be optimized.

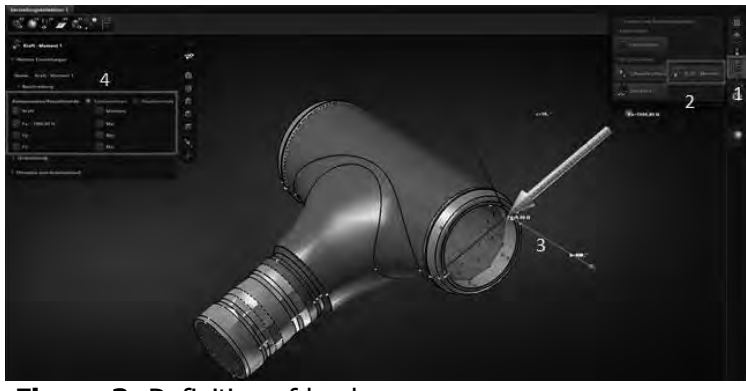

Figure 3: Definition of loads

Based on the defined forces, different load cases acting on the component can be set. After that, the topology optimization of the component is performed, whereby the "non-design spaces" remain filled with material and are not affected by the optimization.

In several iteration steps the design space is optimized considering the "non-design spaces", the defined loads and fixings. In doing so, unneeded material is removed, which has no effect on the force flow in the component. Figure 4 shows an example of the first, the thirtieth and the last iteration step. Finally, the optimized geometry is exported as an STL file and can be used for further processing in the preparation of the manufacturing job.

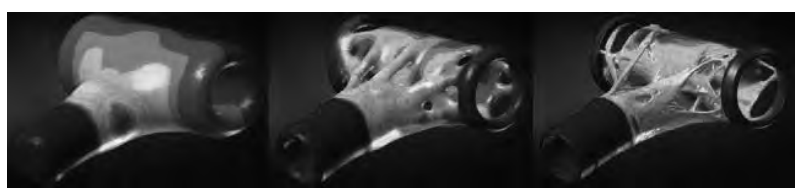

Figure 4: Iteration step 1 (left), iteration step 30 (middle) and iteration step 64 (right)

\section{Preparation of the manufacturing job and simulation of additive manufacturing}

The optimized geometry is designed for the real load cases, but machining post-processing of functional surfaces must also be considered. In the manufacturing job preparation, the corresponding component areas are provided with an offset $(2 \mathrm{~mm})$ so that the functionality of the component is not changed by machining post processing. Figure 5 shows the functional areas of the component with (red) and without (green) offset. 


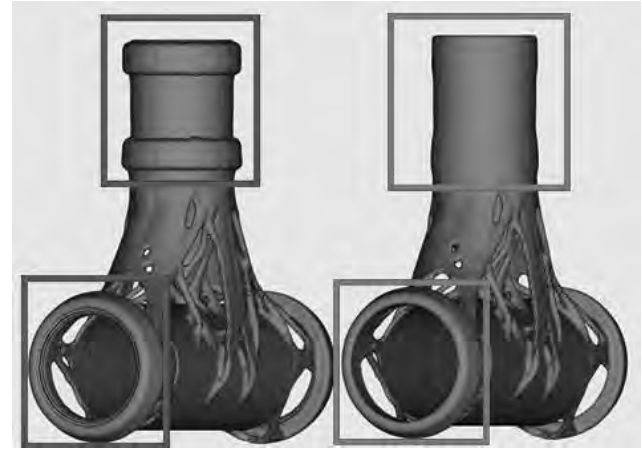

Figure 5: Part with offset for post-processing (left) and without offset (right)

A further step in the preparation of the manufacturing job is the creation of support structures to simulate the additive manufacturing process. For the creation of the the support structure, the orientiation of the component in the build space is highly relevant. The orientation influences the areas in which supports are required, the energy applied for each layer and the required manufacturing time. The layers should have a homogeneous cross-section (without large differences in crosssections) in order to ensure a uniform energy input. Figure 6 shows different orientations of the component. With a suitable selection, the best possible compromise between the production time, the required support and the applied layer energy should be made.

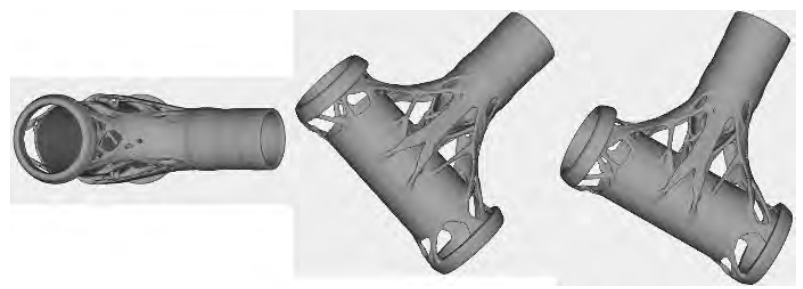

Figure 6: Orientation for minimum manufacturing time (left), minimum support volume (middle) and minimum cross-sectional differences (right)

A compromise of all three parameters is shown in Figure 7 and is used in the following step for the simulation of the additive manufacturing process.

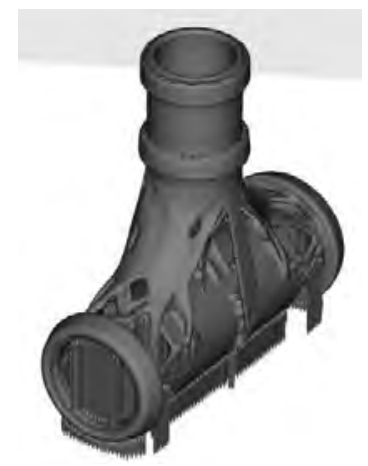

Figure 7: Orientation of the component with supports
For the manufacturing simulation the mechanical calculation approach of "Simufact Additive" is used. It was used for this component because it is a predominantly closed geometry and the residual stresses that arise lead to a negligible deformation of the component [Cf. $2,3,4,5]$. The results of the simulation are shown in Figure 8.

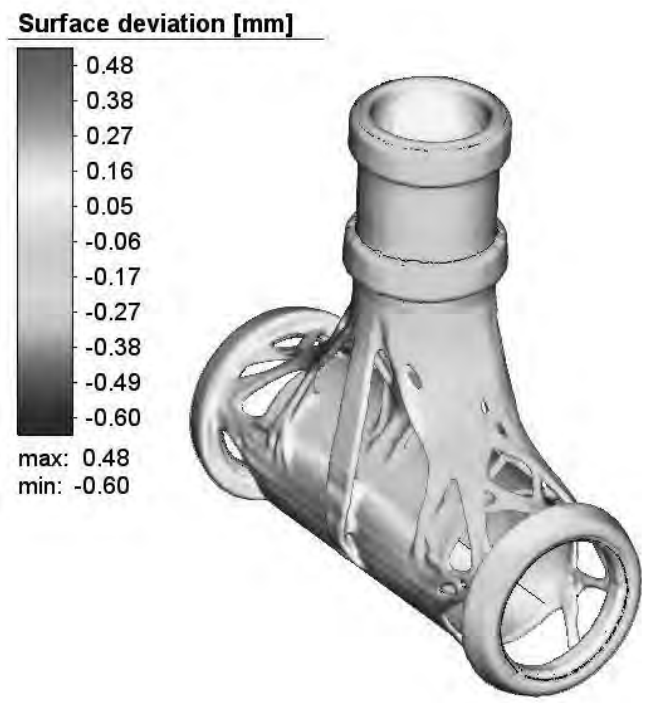

Figure 8: Simulation result of the additive manufacturing process

The calculated deviations occur in uncritical areas and that deformations in the area of the functional surfaces can be reworked by the machining post processing. For this reason, it was decided that this component is not subject to compensation.

\section{Measurement of the manufactured components}

The component was optically measured with a white light scanner system and a comparison was made between the real component and the simulation result. Figure 9 shows that the deviations from the calculated deformation are within $\pm 0.2 \mathrm{~mm}$. Thus, the simulation result can be assumed to be validated, since the existing deviations can be attributed to the machine inaccuracy (melt pool is larger than the laser spot diameter, therefore the component is thickened). 


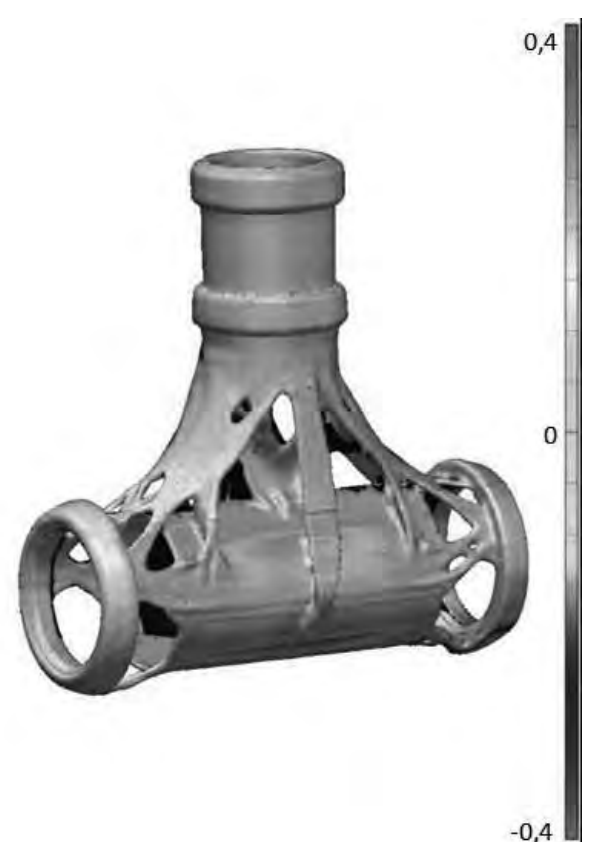

Figure 9: Comparison between simulation result and manufactured component

The measurement of the component was carried out before a machining post processing. As this is required to generate the accuracy, larger deviations can occur in the area of the connection points, as no distortion compensation was used for this component. Decisive for the accuracy of the production result are the areas of the component not to be machined, which are highlighted in Figure 10.

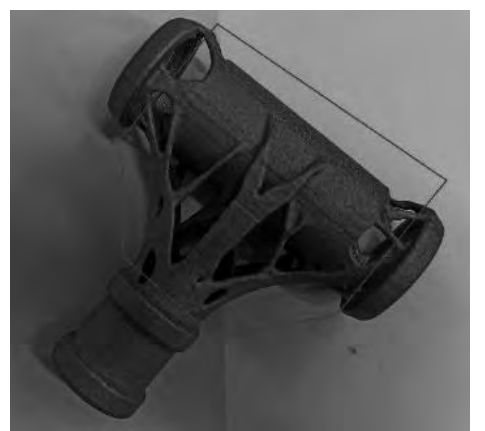

Figure 10: Area relevant for the accuracy assessment

In a second measurement, a target/actual comparison between the real component and the CAD model was carried out. Based on the result in Figure 11, it can be seen that the deviations in the surfaces to be machined are very significant $( \pm 0.4 \mathrm{~mm})$, but the rest of the component shows mainly deviations into the positive range. This is due to the larger melt pool than the laser spot diameter and results in a high volume of the component. Therefore a higher stiffness of the component can be expected and no post processing in these areas is necessary.

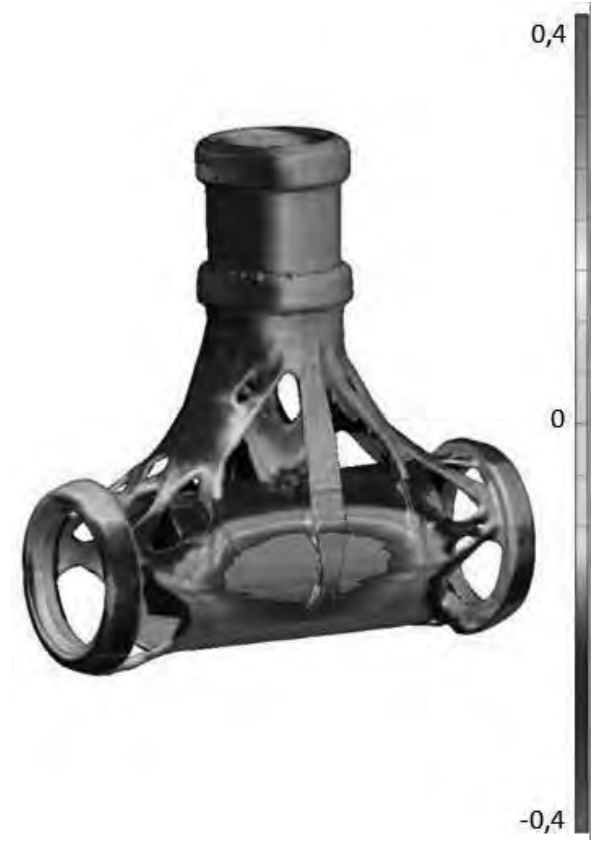

Figure 11: Comparison between CAD model and manufactured component

Based on the measurement result of the target/actual comparison, a sufficient accuracy of the component is available; in addition, the simulation results can be regarded as validated. Subsequently, the functional surfaces were reworked as preparation for the strength tests.

\begin{tabular}{|c|c|c|}
\hline & $\begin{array}{c}\text { Simula- } \\
\text { tion/Manufactured } \\
\text { Part }\end{array}$ & $\begin{array}{c}\text { CAD- } \\
\text { Mod- } \\
\text { ell/Manufactured } \\
\text { Part }\end{array}$ \\
\hline $\begin{array}{l}\text { deviation } \\
\text { in re- } \\
\text { worked } \\
\text { areas } \\
\text { (before } \\
\text { post } \\
\text { pro- } \\
\text { cessing) }\end{array}$ & $\pm 0,1$ & $\pm 0,4$ \\
\hline $\begin{array}{l}\text { deviation } \\
\text { in load } \\
\text { critical } \\
\text { areas (no } \\
\text { post } \\
\text { pro- } \\
\text { cessing) }\end{array}$ & $0-0,2$ & $0-0,4$ \\
\hline & simulation validated & $\begin{array}{c}\text { sufficient accura- } \\
\text { cy }\end{array}$ \\
\hline
\end{tabular}

Table 1: comparison of the deviations in different component areas 


\section{Load test of the topology optimized structure}

For the strength tests, the reworked component was mounted on an existing tensile testing machine with a testing device (Figure 12). For the investigation of the stiffness the clamping of the component has to be taken into account, because within the topology optimization an asymmetrical load distribution was involved. The clamping of the component must correspond to the set loads from the topology optimization in order to obtain usable results.

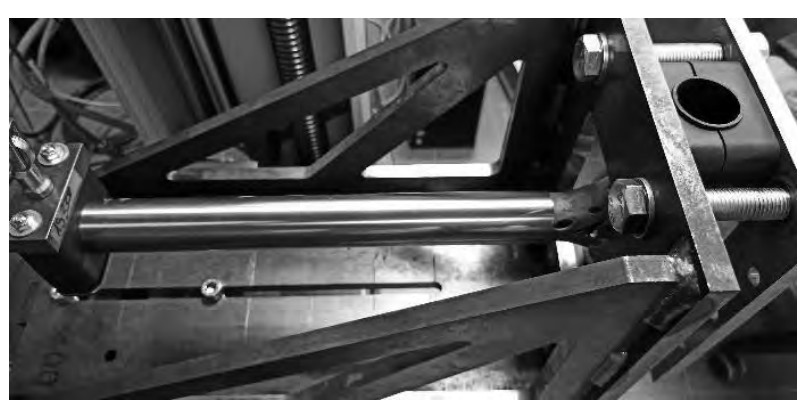

Figure 12: Setting of the component on the test bench

The test was carried out until the component failed, with the focus being on the position of failure. The calculated stress curves from the topology optimization should be able to be checked in this way in real tests. The defined load was at a bending moment of $100 \mathrm{Nm}$. In the test setup, a lever arm of $325 \mathrm{~mm}$ was used to transfer the bending moment to the test specimen. Figure 13 shows that a force of $850 \mathrm{~N}$ was applied to the lever arm before the component failed. This corresponds to a failure bending moment of $276 \mathrm{Nm}$, which clearly fulfills the specification. Further optimization of the component is possible in order to further reduce the weight and still withstand the specified loads.

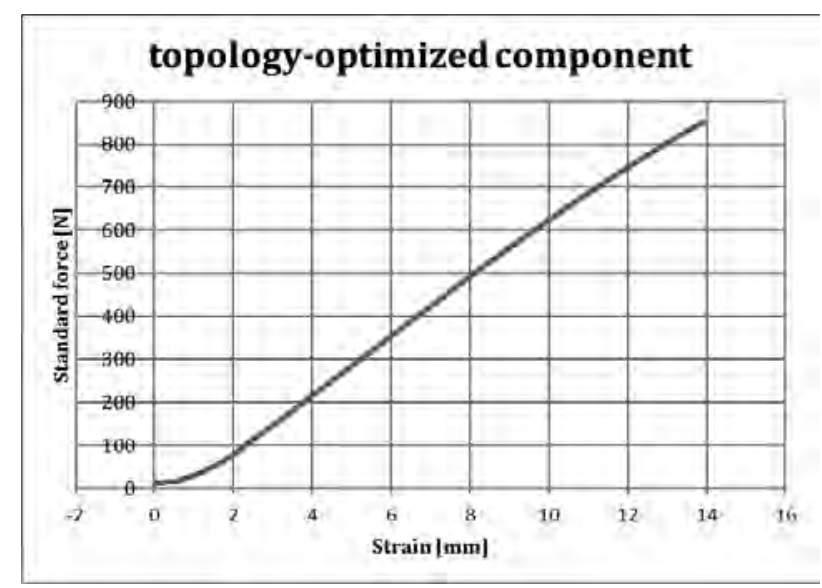

Figure 13: Force-strain diagram of the tested system (optimized component with connecting rods)

With regard to the position of the fracture point, the results from the test and the calculation are in agreement. Figure 14 shows the maximum calculated stress (marked area, left), the real component failure occurs at the predicted location (marked area, right).

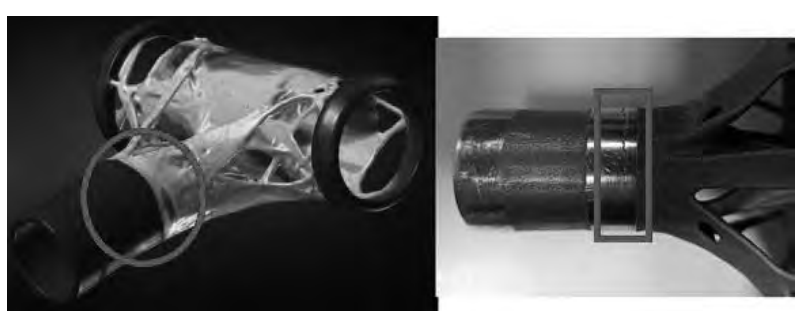

Figure 14: Comparison between calculated stresses (MSC Apex Generative Design, left) and real component failure (right)

Since only the component within the topology optimization was considered and not the connecting rods, a possible explanation is that the notch tension in the transition area has not been considered. In order to avoid this error, a topology optimization of the entire system will be investigated in a future project. 


\section{From the virtual to the real process chain}

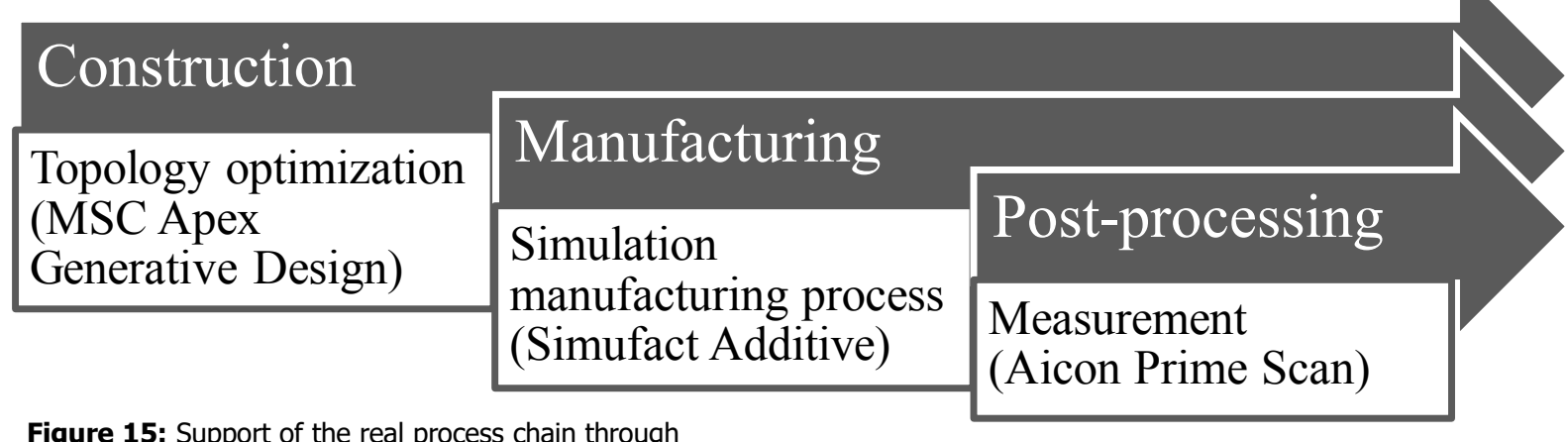

Figure 15: Support of the real process chain through the virtual process chain

\section{References}

Figure 15 illustrates how the virtual process chain has a supporting effect on the real process chain and thus optimizes the manufacturing process. The topology optimization provides a further improvement of the real design and opens up new potential for components. The manufacturing simulation helps to improve real production. By predicting the residual stresses that occur and the resulting distortions, it is possible to print components with the smallest possible deviation. Thus, malfunctioning components can be avoided and production resources can be saved. The measurement of the manufactured components serves to validate the manufacturing simulation results. In addition, the measurement allows the identification of component areas where an adjustment of the design or a machining reworking is necessary to maintain the tolerances.

\section{Future research}

Based on the results of these investigations, further approaches can be derived. On the one hand, a topology optimization of the entire system must be carried out to avoid stresses that have not been considered. Furthermore, a revision of the load-optimized structure (smoothing and closing of small holes to reduce notch effects) is recommended. To improve the load test, an adhesive connection should be made between the component and the connecting tube. Finally, a feedback of the topology-optimized component into a structural analysis for validation of the topology optimization results is planned.

[1] Zentrum für Additive Fertigung; www.ostfalia.de/cms/de/zaf/detail/news/ 9d18688e43a4-11e8-a117-d96edd3be9f9; Access date: 25.06.2020

[2] Mussehl, T.; Rambke, M.: Simufact Additive: Mechanischer oder thermomechanischer Berechnungsansatz? 20. Round Table, Simulation Manufacturing, Tagungsband, Marburg, Mai 22-23, (2019).

[3] Musseh1, T.; Rambke, M.: Rapid-ToolingAnsätze mit dem Metall-Lasersintern - erste Ergebnisse, 19. Round Table, Simulation Manufacturing, Tagungsband, Marburg, Mai 16-17, (2018).

[4] Mussehl, T.; Rambke, R.: Virtualisierung additive Fertigungsprozesse für das Rapid Tooling, 25. Interdisziplinäre Wissenschaftliche Konferenz Mittweida, Tagungsband, Mittweida, Oktober 24-25, (2018).

[5] Mussehl, T.; Rambke, M.: Simulation und Kompensation der Eigenspannungen in der additiven Fertigung, ASIM - Workshop Simulation technischer Systeme/ Grundlagen und Methoden in Modellbildung und Simulation, Tagungsband, Braunschweig, Februar 21 - 22, (2019). 